Research Article

\title{
Investigating the Response Amplitude Operator of a Heaving Pontoon under the Influence of a Submerged Trapezoidal Breakwater
}

\author{
Parviz Ghadimi $\left(\mathbb{D},{ }^{1}\right.$ Mehdi Pourmostafa ${ }^{(D},{ }^{1}$ and Saeed Najafi $\mathbb{D}^{2}$ \\ ${ }^{1}$ Dept. of Maritime Engineering, Amirkabir University of Technology, Tehran, Iran \\ ${ }^{2}$ Ocean Engineering and Technology Department, Iranian National Institute for Oceanography, Tehran, Iran
}

Correspondence should be addressed to Parviz Ghadimi; pghadimi@aut.ac.ir

Received 5 May 2020; Revised 23 September 2020; Accepted 26 October 2020; Published 5 November 2020

Academic Editor: Giuseppe Oliveto

Copyright (c) 2020 Parviz Ghadimi et al. This is an open access article distributed under the Creative Commons Attribution License, which permits unrestricted use, distribution, and reproduction in any medium, provided the original work is properly cited.

\begin{abstract}
Although breakwaters are of great importance to damp the wave energy and protect floating vessels/facilities, they are not fully successful in reducing the waves' height. Therefore, special attention should be paid to accurately investigate the performance of breakwaters. In this paper, the efficiency of a submerged trapezoidal breakwater in the vicinity of a floating pontoon is numerically investigated. First, different simulations are conducted to calibrate the numerical model to achieve an optimum mesh size. Next, a test case is presented for simulation of regular waves passing over a submerged breakwater. Subsequently, the heave response amplitude operator (RAO) of a rectangular pontoon facing an incoming regular wave is studied. A comparison of the obtained results in both test cases with experimental data shows good compliance. Ultimately, the heave motion of a rectangular pontoon behind four different submerged trapezoidal breakwaters facing a regular wave is investigated and different parametric studies are conducted to assess the geometrical effect of the breakwaters. This is the main novelty of the present work which studies the effect of a breakwater on the response amplitude operator (RAO) of a floating structure. In fact, a new version of RAO is presented which includes both incident and transferred wave (which pass over the breakwater) affecting the floating body. Based on the acquired results, the modified RAO of the heaving pontoon shows that breakwater has no effect on the responding frequency, but it does reduce the amplitude of the exciting wave up to $30 \%$.
\end{abstract}

\section{Introduction}

Due to the development of ports and various coastal activities, the protection of facilities and other structures like docked ships in harbors against incoming waves is very important. One of the prevailing methods in this regard is the usage of the submerged breakwater, which has been widely used for many years. Breakwaters are structures that weaken or eliminate the waves. They gradually reduce the wave amplitude and consequently wave energy protects the coastline and natural or manmade structures from potential damage. One of the most important benefits of these structures is the fact that water can flow in/out and this prevents water stagnation. In recent decades, many researchers have performed different experiments on the submerged breakwaters. In 1977, Raman et al. [1] studied a rectangular submerged breakwater. They introduced the transmission coefficient, which was proportional to the transferred wave energy, and showed that, in the case of rectangular breakwaters, the upper width has an important effect on the transmission coefficient. Through conducting a series of experiments, Seelig [2] investigated the transmitted and reflected wave over a breakwater and indicated that these waves are highly affected by the submerged depth and upper width of the breakwater. He also showed that a breakwater of near-zero submergence is efficient in reducing the transmission waves. Jeng et al. [3] experimentally studied the interaction of waves and breakwaters on a sandy seabed and a reflecting wall at the end of the flume. They published two important sets of results from their investigations. They 
showed that the proposed analytical solution by [4] was only valid for near seabed surface in the case of no submerged breakwater. They further demonstrated that the interaction between the incident wave and reflected waves from the breakwater and the wall leads to shorter waves. On the other hand, Alvarez et al. [5] investigated a geotextile tube as a breakwater. This tube was installed as a project along the north beaches of Yucatan in Mexico to prevent erosion that threatened the coast for 15 years. Carevic et al. [6] also conducted a series of experiments on the smoothed breakwater and studied the periodic changes in crossing waves. They showed that, by changing the submerged depth of the breakwater, they can reduce the period of passing wave by about $30 \%$ of the incident wave.

Several researchers have also conducted numerical investigations regarding the interaction of waves and breakwaters. Dick and Brebner [7] conducted a numerical study and showed that a submerged breakwater can dissipate up to 50 percent of the wave energy. Kobayashi and Wurjanto [8] presented a numerical model for simulation of the passing waves over a breakwater in shallow water. Rojanakamthorn et al. [9] presented more accurate equations for the wave propagation over a breakwater and showed that by changing the submerged depth, one can reduce the transmission coefficient to 0.4. Hur and Mizutani [10] developed a numerical model to evaluate hydrodynamic forces on a 3D body on a breakwater. This model was based on the volume of fluid (VOF) approach. Meanwhile, Rambabu and Mani [11] conducted a series of parametric studies on the submerged breakwater. He suggested a crest width to water depth ratio of $B / D=0.7$ to achieve the best transmission coefficient. Subsequently, by holding this ratio as a constant parameter, he showed that, with two breakwaters with $W /$ $B=2$ (distance between breakwater and upper width) ratio, they can reduce the transmission coefficient to 0.6. On the other hand, reference [12] presented two numerical approaches (phase average and phase resolving method) to simulate waves and currents in the vicinity of a breakwater. In a different numerical approach, Chen and Chen [13] developed an adaptive boundary element method to simulate the encounter of incident wave with a submerged breakwater. He showed that the adaptive method increases the efficiency of the computational grids. Christou et al. [14] also used the boundary element method to investigate the passing waves over a rectangular submerged breakwater. Chang and Liou [15] also applied a matching method to study the reflecting and transmitted waves over a breakwater. He first conducted the simulation for a single trapezoidal breakwater and later extended the simulation for a series of breakwaters.

In 2010, Cao et al. [16] developed a numerical model based on the Navier-stokes equations and combined it with $\mathrm{VOF}$ and $k-\varepsilon$ equations to investigate two trapezoidal breakwaters encountering regular waves. Along the same line, Liang et al. [17] used a nonhydrostatical wave model called SWASH (Simulating WAves till SHore) to study two trapezoidal breakwaters. They showed that when the submergence depth ratio is $R / H=1.0$ (i.e., submerged depth to wave height ratio), the efficient distance ratio (distance of breakwater to water depth) of the considered breakwaters is 1.11. In addition, Sindhu and Shirlal [18] studied the transmission coefficient of a submerged reef breakwater. After deriving the preliminary equations, they used MATLAB for simulation purposes and some semiempirical equations were established for determining the transmission coefficient. Li et al. [19] also presented a meshless simple singular boundary method. They simulated an incident wave over one and two breakwaters and showed that the presented model is very efficient.

It is a well-known fact to the researchers in this field that analyses of different aspects of floating bodies are of great importance. The wave loads and motions are the influential factors in designing marine structures and vessels. Beam sea waves are the most dangerous issues among these factors which can capsize the floating structures. Accordingly, various numerical and experimental research has been conducted to predict the motion of different bodies encountering the beam sea waves. Yao et al. [20] experimentally investigated the behavior of 10 different pontoons in waves. He measured the wave amplitude before and after the pontoons. Koutandos et al. [21] studied the hydrodynamic effects of a rectangular submerged breakwater in regular and irregular waves and carried out different experimental measurements for 4 different (fixed pontoon, heaving pontoon, pontoon with a flat plate, and two fixed pontoons) cases. There have also been many numerical works on this topic. For example, Sen [22] developed a potential flow model to estimate the $2 \mathrm{D}$ motion of a floating body in waves. Williams et al. [23] studied the hydrodynamic characteristics of two rectangular pontoons using the boundary element method. Seah and Yeung [24] investigated the sway and roll motion of a floating body with a cylindrical section. Koutandos et al. [25] developed a finite difference model based on Boussinesq equations and simulated a rectangular breakwater in waves.

There exist several methodologies for predicting the maximum roll angle of a floating body. Methods based on statistical extrapolations such as peak over threshold method are some examples. McTaggart [26] used this approach to estimate the maximum roll angle of a Canadian frigate. Pivert et al. [27] also used an analytical method based on the Markov method to evaluate the capsizing probability of a vessel in beam sea waves. He assumed that roll motion is dynamically 1-degree of freedom and damping is linear.

1.1. Motivation of This Work. Based on the presented literature review, it is quite apparent that heaving obstacles and submerged breakwaters have always been studied separately in many cases. However, their combined effects and interactions have not been considered or analyzed. Therefore, in the current paper, the heave motion of a pontoon behind a submerged trapezoidal breakwater is investigated in view of an incident wave and their hydrodynamic interactions are simultaneously analyzed. In fact, the effect of both incident and reflected waves are considered on the floating body in 
this arrangement. This effect is raised in a new form of RAO which could be useful to analyze the behavior of the floating body behind a submerged breakwater. This is the main novelty of the present paper which could be used in the preliminary design of floating structures. The targeted numerical simulations are conducted using the finite volumebased Flow-3D software. Volume of fluid (VOF) and Renormalization-Group (RNG) schemes are applied to model the free surface and turbulence, respectively. Two different simulations are carried out to validate the proposed numerical model. First, the effect of breakwater on the amplitude of an incident wave is investigated. In the second step, the capability of the proposed numerical model is examined to estimate the heaving motion RAO of a floating barge. Both test cases are validated with experimental measurements. Finally, the effect of submerged breakwaters with different geometries in the vicinity of a floating barge is investigated by the presented model. This effect is introduced in the new form of RAO which is affected by the breakwater. To this end, the hydrodynamic performance of submerged breakwaters is examined, and how an efficient breakwater reduces the wave energy and consequently the heave motion of the pontoon is demonstrated. As a real case, building a submerged breakwater in Bandar-e-Abbas, Iran, is under construction with a similar concept. The major function of this breakwater is to protect floating structures nearshore from the incoming waves.

\section{Numerical Model}

2.1. Governing Equations. The equations of motion for the fluid velocity components in three coordinate directions are the continuity and Navier-Stokes equations which are given as

$$
\begin{gathered}
\frac{\partial u_{i}}{\partial x_{i}}=0 \\
\frac{\partial u_{i}}{\partial t}+u_{j} \frac{\partial u_{i}}{\partial x_{j}}=-\frac{1}{\rho} \frac{\partial p}{\partial x_{i}}+\nu \frac{\partial^{2} u_{i}}{\partial x_{j} \partial x_{j}}+g_{i} .
\end{gathered}
$$

Through solving these equations, the pressure and velocity are obtained in the considered computational domain. In this paper, Flow-3D software is used for all numerical simulations. It utilizes the finite volume method for discretizing the Navier-Stokes equations on the structured and orthogonal rectangular grids.

The RNG turbulence model is used to simulate the turbulent effect [28]. Through this approach, statistical methods are applied to derive the averaged equations for turbulent quantities such as turbulent kinetic energy and its dissipation rate. The RNG model uses similar equations as in the $k-\varepsilon$ model. However, equation constants that are found empirically in the standard $k-\varepsilon$ model are derived explicitly in the RNG model. Generally, the RNG model has wider applicability than the standard $k-\varepsilon$ model. In particular, the RNG model is known to describe low-intensity turbulent flows and flows having strong shear regions, more accurately [29].
By using the "unsplit Lagrangian one fluid method," free surface elevation is simulated using the VOF (volume of fluid) scheme [30]. The VOF transport equation is as follows:

$$
\frac{\partial \alpha}{\partial t}+\vec{\nabla} \cdot(\alpha \vec{u})=0
$$

where $\alpha$ is the volume of the faction of the fluid and takes the following values:

$$
\alpha= \begin{cases}1, & \text { cell inside water, } \\ 0, & \text { cell inside Air, } \\ 0<\alpha<1, & \text { for transitional area. }\end{cases}
$$

In this scheme, $\alpha=1$ for a specified cell implies that the cell is full of fluid (water), and $\alpha=0$ denotes the void cells. In the void cells, there is no mass and the atmosphere pressure would apply. $0<\alpha<1$ also shows the percentage of the existing fluid in a particular cell. To simulate the heaving motion of a submerged object, the GMO (General Moving Object) model in Flow-3D is used. This model solves the translation motion equations:

$$
\vec{F}=m \cdot \frac{d \vec{V}}{d t},
$$

where $\vec{V}$ is the linear velocity of the center of gravity of the submerged object and $\vec{F}$ is the exerted force on the body which is a summation of gravitational and hydrodynamic forces.

2.2. Mesh. Flow-3D uses FAVOR (Fractional-Area-Volume-Obstacle-Representation) technique to model the solid obstacle/moving bodies. This method is based on the area/volume fraction of the structured grids to capture the complex geometrics. In this technique, the accuracy of each obstacle geometry depends on the mesh size. Therefore, for the complex geometry, it is necessary to increase the number of cells for detecting more details of the obstacle geometry. On the other hand, increasing the number of mesh would in turn increase the computational times. To deal with this important issue, many users use local mesh block around complex geometries $[31,32]$. In this paper, based on the mesh independence study in the following sections, it is quite apparent that no mesh block is necessary and hence a single structured mesh is utilized.

2.3. Boundary Conditions. Boundary conditions applied for all the considered cases in this paper are displayed in Figure 1 . To reduce the wave reflection at the end of the numerical flume, its length is increased by at least 3 times of the wavelength behind the pontoon. It should also be noted that, for the condition at the outlet, the "allow fluid to enter at outflow boundary" option in Flow-3D software is employed. To increase the numerical stability, the wave boundary condition is applied on all surfaces as the initial condition. 


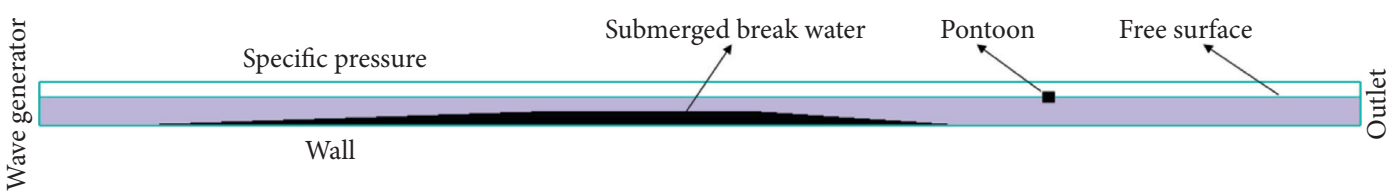

FIgURE 1: Schematic boundary conditions for the numerical wave flume.

\section{Validation}

In this section, two numerical tests are presented to validate the proposed numerical model. First, the simulation of free surface flow over a submerged breakwater is carried out and the capability of the numerical model in creating the linear wave is demonstrated. Subsequently, the heave motion of a submerged pontoon is estimated via a numerical model and the results are compared against experimental data. This test indicates the capability of the proposed model in predicting the heave motion in a single linear wave.

\subsection{Simulation of Free Surface over a Submerged Trapezoidal} Breakwater. The first test case for validation of the proposed numerical simulation involves wave propagation over a submerged breakwater. The experimental layout [33] of the considered test containing the breakwater dimensions and the overall flume length is displayed in Figure 2. The main goal of this experiment was the investigation of the frequency spectrum for waves travelling over a submerged breakwater. The incoming wave height is $2 \mathrm{~cm}$ with a period of 2.02 seconds.

The geometry of the breakwater is produced using CAD software and the output is imported to the solver. Twodimensional simulation is conducted solving the NavierStokes equations by combining the VOF and RNG methods. Water surface elevation over a breakwater is measured at four different positions ( $x=5.2,12.5,14.5,17.3$ meter $)$ and compared against the experimental data [33]. Figure 3 shows the position of the elevation sensors from the original axes of the flume.

In order to apply the most appropriate mesh size for the computational domain, a grid independence study is performed in order to ensure that the obtained results are independent of the grid size and the computational CPU time is efficient. For this reason, four different mesh sizes are used. The mesh sizes are illustrated in Table 1 In this case, relative error (the norm of the error vector, $\sqrt{\sum e_{i}^{2}}$ ) has been computed based on the deviation of free surface elevation from the experimental value.

Figure 4 shows the surface elevation of water at $x=14.5 \mathrm{~m}$. As evident in this figure, the results show a negligible effect between grid 3 and grid 4 cases. Although grid 2 captures the free surface in an appropriate way (relative error is less than 5\%), but because of two reasons stated below, a cell size similar to grid 3 is used for all the remaining simulations.

(1) Refining the cell sizes from grid 2 to grid 3 would reduce the error below $2 \%$, which, according to the simulation time, is acceptable. However, by moving toward grid 4, no major changes are seen in the free surface deformation.

(2) As Flow-3D does not use moving mesh for simulating the moving objects (as mentioned before) and since there is a moving object in the main modeled case, it becomes necessary to use more refinements to ensure that GMO model correctly simulate the moving pontoon.

Water surface elevations at $x=5.2,12.5,17.3$ are also displayed in Figures 5-7.

As observed in Figures 5-7, the proposed numerical model can simulate the considered waves well enough.

\subsection{Heave Response Amplitude of a Submerged Pontoon.} The second test is conducted to assess the ability of the numerical solver in estimating the response of a submerged body encountering a regular wave. To achieve this goal, the RAO curve for a rectangular pontoon is studied. The simulated domain is illustrated in Figure 8. The flume length is $63.0 \mathrm{~m}$ and the water depth is $1.25 \mathrm{~m}$. A rectangular pontoon $(d \times 2 b)$ is situated at the center of the flume which is only allowed to heave freely. Table 2 shows the dimensions of the flume and heaving pontoon.

An incident regular wave is considered with wave number $k$, amplitude $A$, and wave frequency $\omega$. The wellknown linear dissipation equation $\left(\omega^{2}=g k \tanh (k h)\right)$ is utilized to calculate the wave frequency in which $g$ is the gravity acceleration. It is also known that the wave period is $T=2 \pi / \omega$. All incident waves are assumed to have a fixed value of $A k=0.05$ and $A k=0.1$. To draw the RAO curve for the heave motion, seven different simulations with different wave frequencies are carried out. Specifications of the considered waves are shown in Table 3.

For each wavenumber, $40 \mathrm{~s}$ simulation is performed. The heave motion curve is shown in Figure 9.

As observed in Figure 9, the amplitude of heave motion can be assumed to be periodically constant after about 25 seconds. Accordingly, one may assume that the last 15 seconds of the heave motion is more of a stable heave response of the pontoon. By applying the Fast Fourier transform to the heave response, the induced frequency and its amplitude are achieved in Figure 10.

As seen in the frequency spectrum of Figure 10, the induced frequency is $0.8621(\mathrm{~Hz})$ and the amplitude is $0.01448(\mathrm{~m})$. For all other simulations, the corresponding FFT is applied. Tables 4 and 5 show all the responded frequencies and amplitudes for different incident waves.

As observed in Table 5, the heave response frequency of the pontoon is approximately the same as the exciting frequency. This shows that the submerged pontoon has 


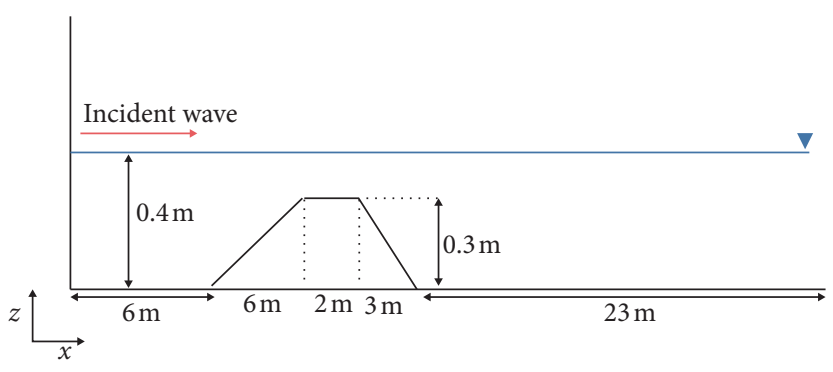

Figure 2: Schematic of the breakwater and flume.

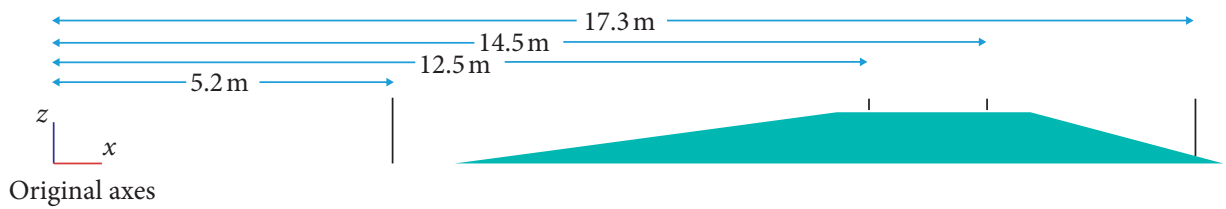

Figure 3: Positions of the sensors for measuring the free surface elevation.

TABle 1: Mesh sizes of the applied grids.

\begin{tabular}{lccc}
\hline & Grid size (cm) & Relative error (\%) & $\begin{array}{c}\text { Computational time } \\
(\mathrm{min})\end{array}$ \\
\hline Grid 1 & $1.0 \times 1.0$ & 6.3 & 12 \\
Grid 2 & $0.87 \times 0.87$ & 2.97 & 41 \\
Grid 3 & $0.6 \times 0.6$ & 1.93 & 234 \\
Grid 4 & $0.5 \times 0.5$ & 1.65 & 352 \\
\hline
\end{tabular}

exactly the same frequency as that of the incident wave. Tables 4 and 5 also show the errors in predicting the response frequency. The maximum errors in Cases 1 and 2 are $8.16 \%$ and $1.69 \%$, respectively. This is indicative of the fact that the proposed model can predict the exciting frequency well enough.

Another critical parameter for the assessment of the accuracy of the simulation is the response amplitude operator (RAO). The response amplitude operator is normally defined as the ratio of the linear motion response and linear incident wave amplitude. In Figure 11, the RAO curve is plotted versus different values of $k b$ and compared with experimental results [34] and numerical data [35]. The numerical data is based on a commercial radiation-diffraction solver. On the other hand, in the experimental work, a sensor is situated at the submerged box to measure the heave motion caused by the wave impact [34].

\section{Heaving Motion of the Rectangular Pontoon behind a Trapezoidal Breakwater}

This section addresses the main issue of the paper which corresponds to the investigation of the heave amplitude of a submerged pontoon behind a trapezoidal breakwater. For this purpose, the heave motion of a rectangular pontoon behind the four different submerged breakwaters is investigated. The computational domain is schematically shown in Figure 12. The pontoon dimensions and its distance from the breakwaters are assumed to be constant (Table 6) in all considered cases. Four types of breakwater dimensions (midsection and its height) are shown in Table 7.

Regular waves with displayed characteristics in Table 8 are generated in the numerical flume. These waves are selected because the numerical validations are also conducted for the same parameters.

In each case, the pontoon is free to heave due to the incident wave. The time history of the heave diagram versus the time is logged in each simulation.

Similar to the validation case, which is presented in the previous section, by applying a fast Fourier transform for each heave time history, the responding frequency and amplitude of the pontoon is calculated. Tables 9-12 show the RAO values and errors in responding frequencies for different breakwaters.

The RAO curves for the heaving pontoon are plotted together (with and without the breakwater) for all four breakwaters in Figures 13-16.

It is clearly apparent that, by adding the submerged breakwater, the response amplitude of the floating barge would decrease. In other words, its motions damp out, but for a better comparison of the performance of the breakwaters, their damping energy can be compared together. The damping energy factor $(\Lambda)$ is defined as follows:

$$
\Lambda=\int_{0.3}^{1} \frac{\mathrm{RAO}_{\text {for pontoon without breakwater }}-\mathrm{RAO}_{\text {for pontoon with breakwater }}}{\mathrm{RAO}_{\text {for pontoon without breakwater }}} \times 100
$$




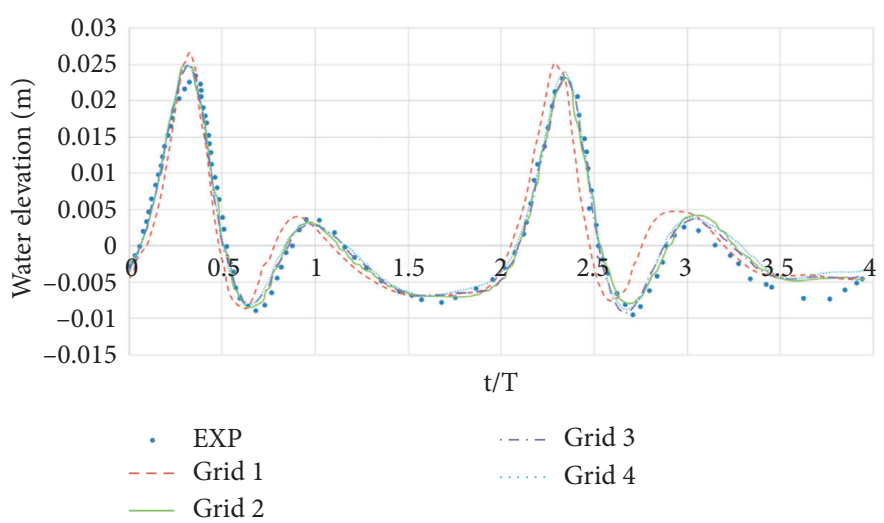

FIGURE 4: Water surface elevation at $x=14.5$.

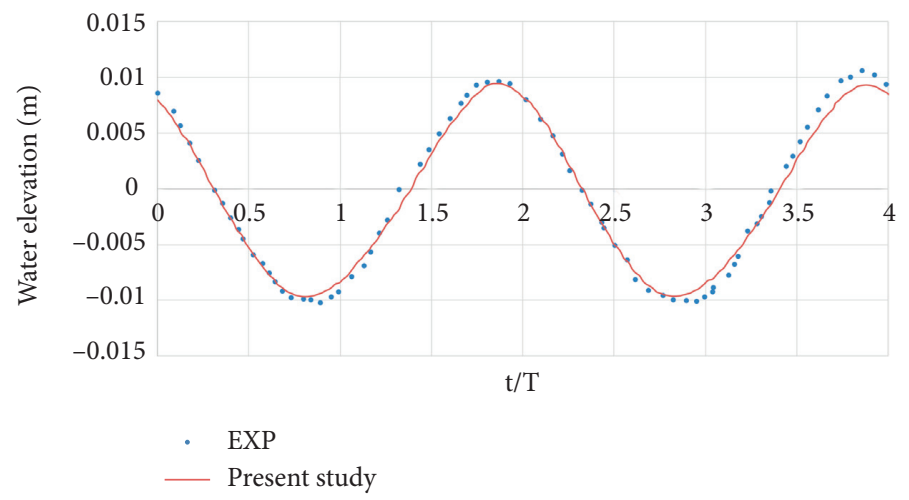

FIGURE 5: Water surface elevation at $x=5.2$.

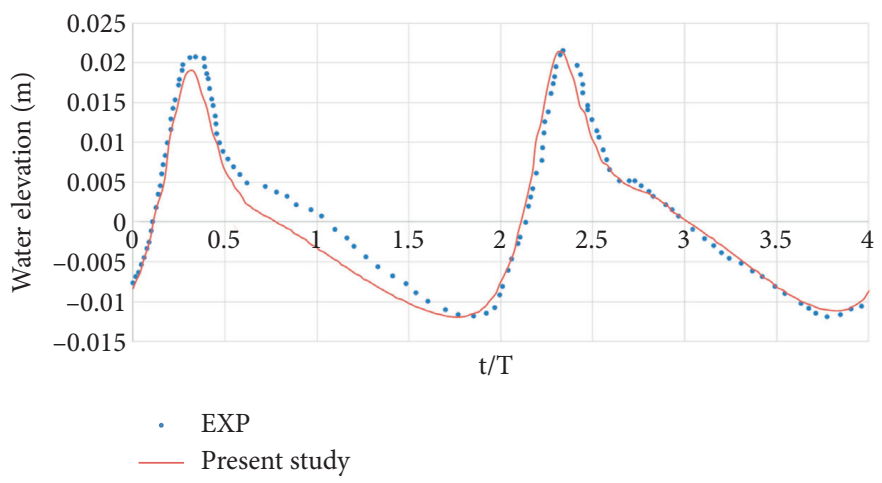

FIGURE 6: Water surface elevation at $x=12.5$.

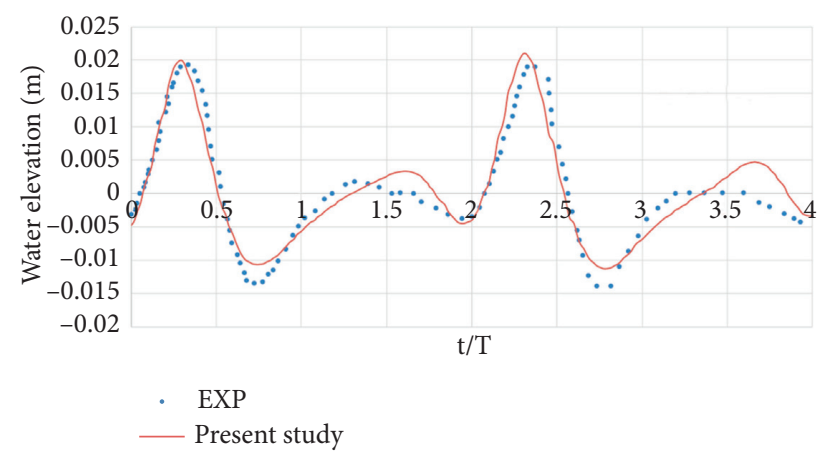

Figure 7: Water surface elevation at $x=17.3$. 


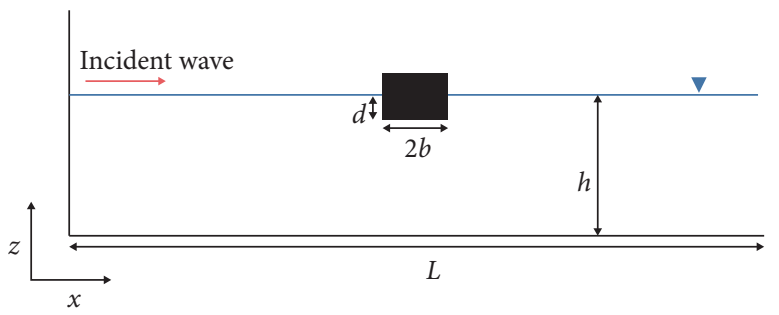

FIGURE 8: Schematic of the numerical wave flume.

TABle 2: Dimensions of the considered flume and heaving pontoon.

\begin{tabular}{lc}
\hline Dimensions & Value (in meter) \\
\hline Length of flume $(L)$ & 63.0 \\
Water depth $(h)$ & 1.25 \\
Height of pontoon $(d)$ & 0.25 \\
Half-breath of pontoon $(b)$ & 0.25 \\
\hline
\end{tabular}

TABle 3: Waves specifications.

\begin{tabular}{cccccccccc}
\hline \multicolumn{3}{c}{ Waves specification (Case 1) } & \multicolumn{4}{c}{ Waves specification (Case 2) } \\
$A k$ & $\mathrm{~kb}$ & $A$ & $T$ & $f$ & $A k$ & $\mathrm{~kb}$ & $A$ & $T$ & $f$ \\
\hline 0.05 & 0.2 & 0.063 & 2.570 & 0.389 & 0.1 & 0.2 & 0.125 & 2.570 & 0.389 \\
0.05 & 0.4 & 0.031 & 1.615 & 0.619 & 0.1 & 0.4 & 0.063 & 1.615 & 0.619 \\
0.05 & 0.5 & 0.025 & 1.430 & 0.700 & 0.1 & 0.5 & 0.050 & 1.430 & 0.700 \\
0.05 & 0.6 & 0.021 & 1.298 & 0.770 & 0.1 & 0.6 & 0.042 & 1.298 & 0.770 \\
0.05 & 0.7 & 0.018 & 1.200 & 0.833 & 0.1 & 0.7 & 0.036 & 1.200 & 0.833 \\
0.05 & 0.8 & 0.016 & 1.123 & 0.891 & 0.1 & 0.8 & 0.031 & 1.123 & 0.891 \\
0.05 & 1.0 & 0.013 & 1.000 & 0.997 & 0.1 & 1.0 & 0.025 & 1.000 & 0.997 \\
\hline
\end{tabular}

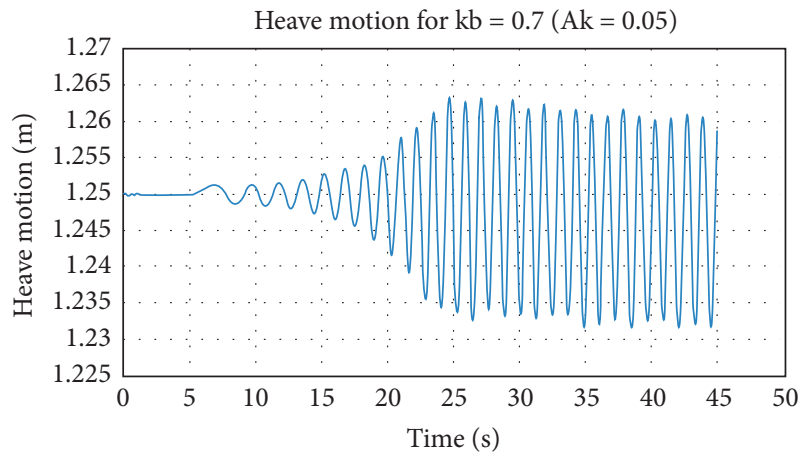

FIgURE 9: Time history of the heave motion of the pontoon at $A k=$ 0.05 and $\mathrm{kb}=0.7$.

The damping energy capability represents the energy reduction percentage of each breakwater. The values of $\Lambda$ for all four cases are shown in Table 13.

It is observed that height has a greater effect on the breakwater's performance than its length. In fact, a 50\% increase in the breakwater height is more effective than a $50 \%$ increase in the breakwater length. According to the calculated results, by increasing the height in this type of breakwater, the energy reduces up to $30 \%$, while increasing its length only damps the energy up to $2 \%$.

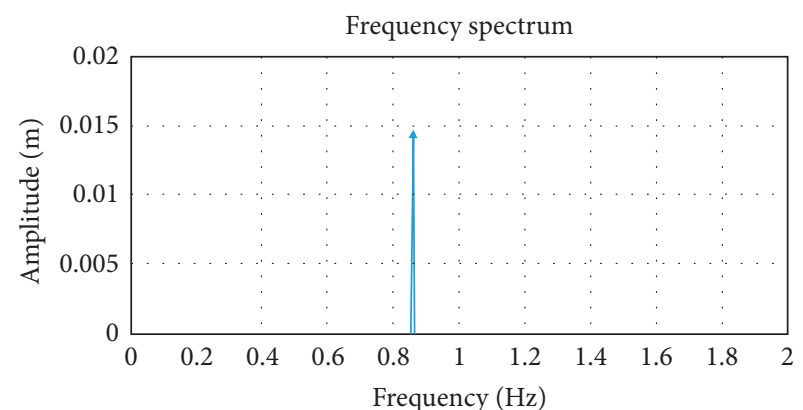

Figure 10: Excited amplitude and frequency of the heaving pontoon at $A k=0.05$ and $\mathrm{kb}=0.7$.

TABLE 4: Amplitude and frequency of the heaving pontoon in Case 1.

\begin{tabular}{|c|c|c|c|c|}
\hline \multicolumn{5}{|c|}{ Waves specification (Case 1) } \\
\hline \multicolumn{2}{|c|}{ Exciting waves } & \multicolumn{2}{|c|}{$\begin{array}{l}\text { Response of } \\
\text { pontoon } \\
\text { (from FFT) }\end{array}$} & \multirow[t]{2}{*}{ Frequency error (\%) } \\
\hline$A$ & $f$ & $A$ & $f$ & \\
\hline 0.063 & 0.389 & 0.06435 & 0.39680 & 1.94 \\
\hline 0.031 & 0.619 & 0.03774 & 0.80910 & 4.34 \\
\hline 0.025 & 0.700 & 0.03588 & 0.92590 & 5.46 \\
\hline 0.021 & 0.770 & 0.02523 & 1.16700 & 7.56 \\
\hline 0.018 & 0.833 & 0.01403 & 1.50900 & 3.33 \\
\hline 0.016 & 0.891 & 0.00774 & 1.85200 & 3.72 \\
\hline 0.013 & 0.997 & 0.00254 & 2.07400 & 8.16 \\
\hline
\end{tabular}

TABle 5: Amplitude and frequency of the heaving pontoon in Case 2.

\begin{tabular}{|c|c|c|c|c|}
\hline \multicolumn{5}{|c|}{ Waves specification (Case 2) } \\
\hline \multicolumn{2}{|c|}{ Exciting waves } & \multicolumn{2}{|c|}{$\begin{array}{l}\text { Response of } \\
\text { pontoon } \\
\text { (from FFT) }\end{array}$} & \multirow[t]{2}{*}{ Frequency error (\%) } \\
\hline$A$ & $f$ & $A$ & $f$ & \\
\hline 0.125 & 0.389 & 0.125 & 0.385 & 1.17 \\
\hline 0.063 & 0.619 & 0.070 & 0.611 & 1.34 \\
\hline 0.050 & 0.700 & 0.060 & 0.695 & 0.7 \\
\hline 0.042 & 0.770 & 0.046 & 0.772 & 0.19 \\
\hline 0.036 & 0.833 & 0.024 & 0.833 & 0.01 \\
\hline 0.031 & 0.891 & 0.014 & 0.893 & 0.17 \\
\hline 0.025 & 0.997 & 0.004 & 0.980 & 1.69 \\
\hline
\end{tabular}

Therefore, it is quite apparent that it is very efficient to increase the height of the breakwaters rather than its length in terms of damping energy capability. 


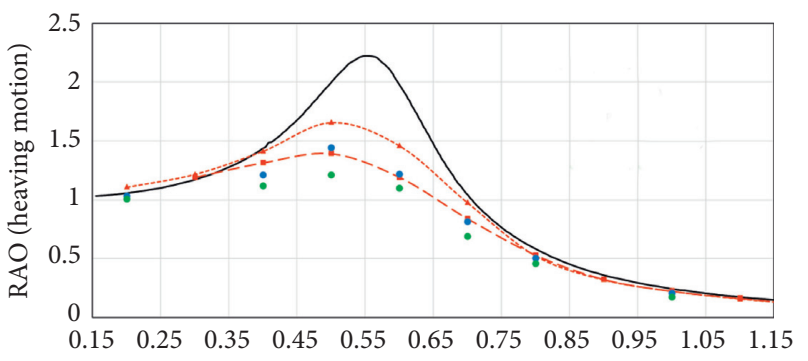

$\mathrm{kb}$

$$
\begin{aligned}
& \text { — WAMIT - Present study }(\mathrm{AK}=0.05) \\
& \text { - - } \operatorname{EXP}(\mathrm{AK}=0.05) \quad \text { Present study }(\mathrm{AK}=0.1) \\
& -\operatorname{EXP}(\mathrm{AK}=0.10)
\end{aligned}
$$

Figure 11: Heave motion RAO of a pontoon.

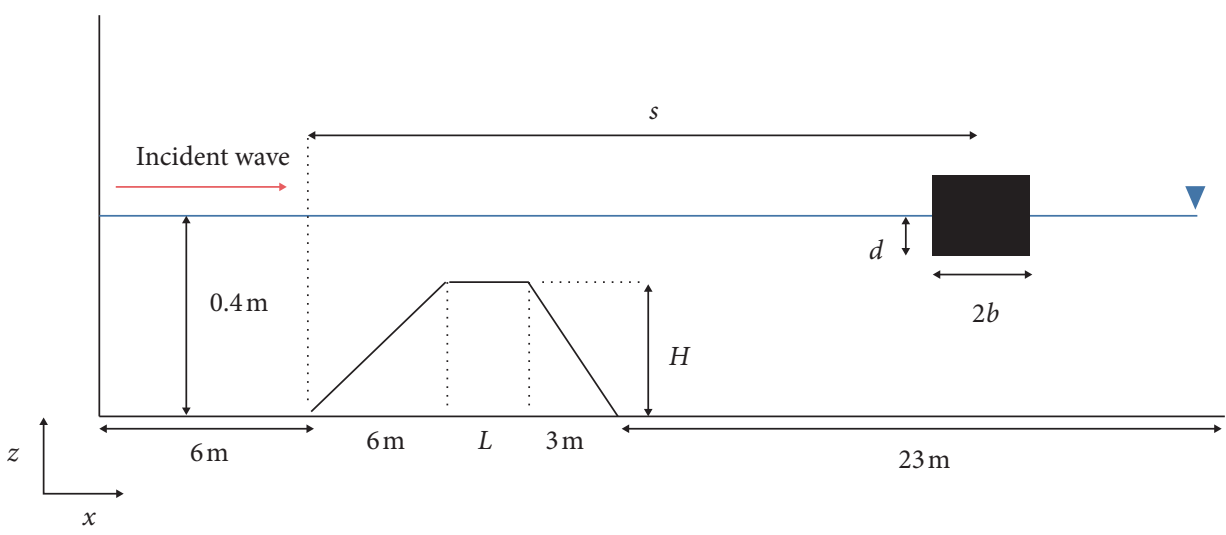

FIGURE 12: Schematics of the submerged breakwater and heaving pontoon.

TABLE 6: The heaving pontoon dimensions.

\begin{tabular}{lcc}
\hline & Pontoon dimensions (meter) \\
\hline$b$ & 0.08 \\
$d$ & 0.08 \\
$s$ & 13 \\
\hline
\end{tabular}

TABLE 7: Four different breakwater dimensions.

\begin{tabular}{lcc}
\hline & Length of midsection $(L)(\mathrm{m})$ & Height $(H)(\mathrm{m})$ \\
\hline Breakwater 1 & 3 & 0.3 \\
Breakwater 2 & 2 & 0.3 \\
Breakwater 3 & 3 & 0.2 \\
Breakwater 4 & 2 & 0.2 \\
\hline
\end{tabular}

TABle 8: Wave characteristics.

\begin{tabular}{lcccc}
\hline \multicolumn{5}{c}{ Wave specification } \\
$A k$ & $\mathrm{~kb}$ & $A$ & $T$ & $f$ \\
\hline 0.05 & 0.3 & 0.013 & 1.089 & 0.918 \\
0.05 & 0.4 & 0.01 & 0.914 & 1.094 \\
0.05 & 0.5 & 0.008 & 0.808 & 1.238 \\
0.05 & 0.6 & 0.007 & 0.734 & 1.362 \\
0.05 & 0.7 & 0.006 & 0.679 & 1.473 \\
0.05 & 0.8 & 0.005 & 0.635 & 1.576 \\
0.05 & 0.9 & 0.004 & 0.598 & 1.672 \\
0.05 & 1 & 0.004 & 0.567 & 1.762 \\
\hline
\end{tabular}

TABle 9: Amplitude and frequency of the heaving pontoon for breakwater number 1 .

\begin{tabular}{ccccccc}
\hline \multicolumn{7}{c}{ Wave specifications } \\
Response of \\
$\mathrm{kb}$ & Exciting waves & \multicolumn{2}{c}{$\begin{array}{c}\text { pontoon } \\
\text { (from FFT) }\end{array}$} & $\begin{array}{c}\text { Frequency } \\
\text { error (\%) }\end{array}$ & RAO \\
& $A$ & $f$ & $A$ & $f$ & & \\
\hline 0.3 & $1.33 E-02$ & 0.918 & $1.36 E-02$ & 0.924 & 0.556 & 1.017 \\
0.4 & $1.00 E-02$ & 1.094 & $1.12 E-02$ & 1.100 & 0.510 & 1.121 \\
0.5 & $8.00 E-03$ & 1.238 & $9.82 E-03$ & 1.267 & 2.355 & 1.228 \\
0.6 & $6.67 E-03$ & 1.362 & $5.59 E-03$ & 1.374 & 0.897 & 0.839 \\
0.7 & $5.71 E-03$ & 1.473 & $2.08 E-03$ & 1.478 & 0.326 & 0.363 \\
0.8 & $5.00 E-03$ & 1.576 & $5.70 E-04$ & 1.566 & 0.624 & 0.114 \\
0.9 & $4.44 E-03$ & 1.672 & $2.08 E-04$ & 1.659 & 0.764 & 0.047 \\
1.0 & $4.00 E-03$ & 1.762 & $1.85 E-04$ & 1.752 & 0.587 & 0.046 \\
\hline
\end{tabular}

The proposed numerical model with similar charts could be used to analyze the performance of submerged breakwaters. On the other hand, the motion of any floating body could be estimated with the same procedure. 
TABLE 10: Amplitude and frequency of the heaving pontoon for breakwater number 2.

\begin{tabular}{|c|c|c|c|c|c|c|}
\hline \multirow{3}{*}{$\mathrm{kb}$} & \multicolumn{6}{|c|}{ Wave specifications } \\
\hline & \multicolumn{2}{|c|}{ Exciting waves } & \multicolumn{2}{|c|}{$\begin{array}{l}\text { Response of pontoon } \\
\text { (from FFT) }\end{array}$} & \multirow{2}{*}{ Frequency error (\%) } & \multirow{2}{*}{$\mathrm{RAO}$} \\
\hline & $A$ & $f$ & $A$ & $f$ & & \\
\hline 0.3 & $1.33 E-02$ & 0.918 & $1.23 E-02$ & 0.941 & 2.450 & 0.921 \\
\hline 0.4 & $1.00 E-02$ & 1.094 & $9.85 E-03$ & 1.070 & 2.231 & 0.985 \\
\hline 0.5 & $8.00 E-03$ & 1.238 & $9.61 E-03$ & 1.273 & 2.840 & 1.202 \\
\hline 0.6 & $6.67 E-03$ & 1.362 & $5.81 E-03$ & 1.372 & 0.750 & 0.872 \\
\hline 0.7 & $5.71 E-03$ & 1.473 & $2.59 E-03$ & 1.468 & 0.353 & 0.453 \\
\hline 0.8 & $5.00 E-03$ & 1.576 & $6.17 E-04$ & 1.575 & 0.053 & 0.123 \\
\hline 0.9 & $4.44 E-03$ & 1.672 & $2.78 E-04$ & 1.695 & 1.389 & 0.062 \\
\hline 1.0 & $4.00 E-03$ & 1.762 & $2.10 E-04$ & 1.748 & 0.814 & 0.052 \\
\hline
\end{tabular}

TABLE 11: Amplitude and frequency of the heaving pontoon for breakwater number 3.

\begin{tabular}{|c|c|c|c|c|c|c|}
\hline \multicolumn{7}{|c|}{ Wave specifications } \\
\hline \multirow[t]{2}{*}{$\mathrm{kb}$} & \multicolumn{2}{|c|}{ Exciting waves } & \multicolumn{2}{|c|}{$\begin{array}{l}\text { Response of pontoon } \\
\quad(\text { from FFT) }\end{array}$} & \multirow[t]{2}{*}{ Frequency error (\%) } & \multirow[t]{2}{*}{$\mathrm{RAO}$} \\
\hline & $A$ & $f$ & $A$ & $f$ & & \\
\hline 0.3 & $1.33 E-02$ & 0.918 & $1.12 E-02$ & 0.922 & 0.349 & 0.838 \\
\hline 0.4 & $1.00 E-02$ & 1.094 & $1.15 E-02$ & 1.096 & 0.144 & 1.147 \\
\hline 0.5 & $8.00 E-03$ & 1.238 & $9.93 E-03$ & 1.242 & 0.335 & 1.241 \\
\hline 0.6 & $6.67 E-03$ & 1.362 & $6.33 E-03$ & 1.372 & 0.750 & 0.950 \\
\hline 0.7 & $5.71 E-03$ & 1.473 & $2.85 E-03$ & 1.469 & 0.285 & 0.498 \\
\hline 0.8 & $5.00 E-03$ & 1.576 & $9.15 E-04$ & 1.579 & 0.201 & 0.183 \\
\hline 0.9 & $4.44 E-03$ & 1.672 & $3.22 E-04$ & 1.659 & 0.764 & 0.072 \\
\hline 1.0 & $4.00 E-03$ & 1.762 & $2.34 E-04$ & 1.750 & 0.700 & 0.059 \\
\hline
\end{tabular}

TABLE 12: Amplitude and frequency of the heaving pontoon for breakwater number 4.

\begin{tabular}{|c|c|c|c|c|c|c|}
\hline \multirow{3}{*}{$\mathrm{kb}$} & \multicolumn{6}{|c|}{ Wave specifications } \\
\hline & \multicolumn{2}{|c|}{ Exciting waves } & \multicolumn{2}{|c|}{$\begin{array}{l}\text { Response of pontoon } \\
\text { (from FFT) }\end{array}$} & \multirow[t]{2}{*}{ Frequency error (\%) } & \multirow[t]{2}{*}{$\mathrm{RAO}$} \\
\hline & $A$ & $f$ & $A$ & $f$ & & \\
\hline 0.3 & $1.33 E-02$ & 0.918 & $1.36 E-02$ & 0.924 & 0.599 & 1.016 \\
\hline 0.4 & $1.00 E-02$ & 1.094 & $1.12 E-02$ & 1.086 & 0.769 & 1.118 \\
\hline 0.5 & $8.00 E-03$ & 1.238 & $1.05 E-02$ & 1.251 & 1.062 & 1.310 \\
\hline 0.6 & $6.67 E-03$ & 1.362 & $5.66 E-03$ & 1.319 & 3.142 & 0.849 \\
\hline 0.7 & $5.71 E-03$ & 1.473 & $3.20 E-03$ & 1.493 & 1.344 & 0.561 \\
\hline 0.8 & $5.00 E-03$ & 1.576 & $8.01 E-04$ & 1.591 & 0.963 & 0.160 \\
\hline 0.9 & $4.44 E-03$ & 1.672 & $3.85 E-04$ & 1.673 & 0.073 & 0.087 \\
\hline 1.0 & $4.00 E-03$ & 1.762 & $1.92 E-04$ & 1.764 & 0.094 & 0.048 \\
\hline
\end{tabular}

TABLE 13: Damping energy capability $\Lambda$ for different breakwaters.

\begin{tabular}{llll}
\hline & $x$ & $y$ & $\Lambda(\%)$ \\
\hline Breakwater 1 & 3 & 0.3 & 38.504 \\
Breakwater 2 & 2 & 0.3 & 36.292 \\
Breakwater 3 & 3 & 0.2 & 28.661 \\
Breakwater 4 & 2 & 0.2 & 27.413 \\
\hline
\end{tabular}




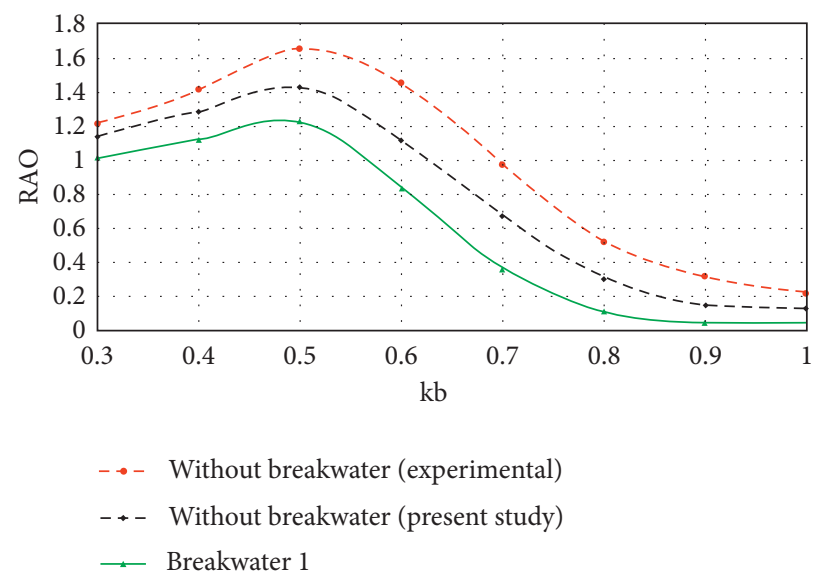

FIGURE 13: RAO curve for a heaving pontoon, with and without breakwater number 1 .

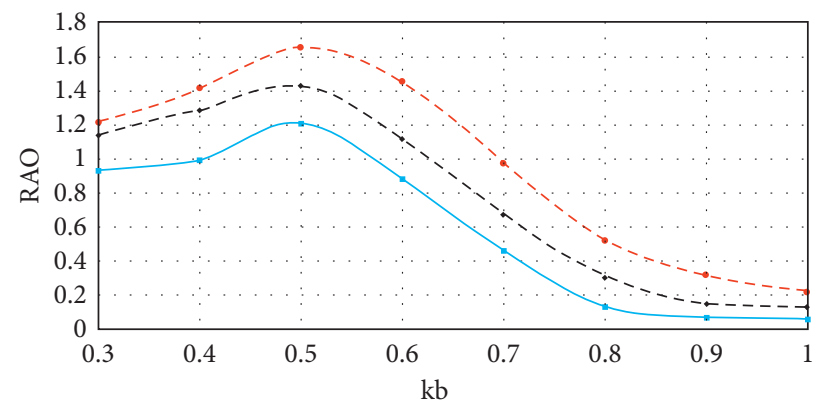

$\ldots-$ Without breakwater (experimental)

-+- Without breakwater (present study)

$\rightarrow$ Breakwater 2

FIGURE 14: RAO curve for a heaving pontoon, with and without breakwater number 2 .

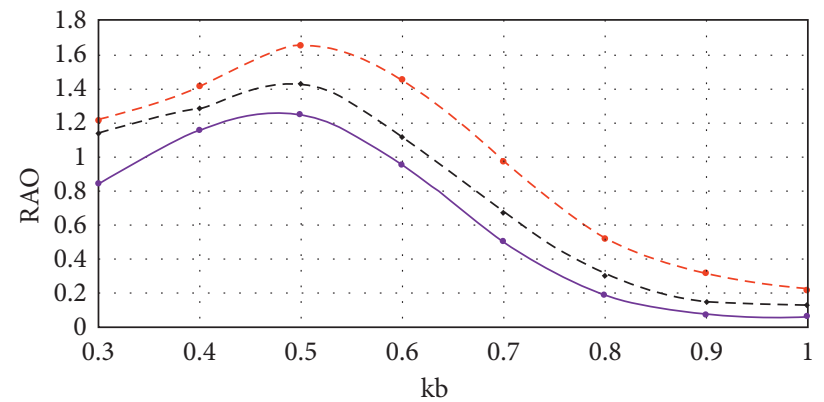

$\ldots$ - Without breakwater (experimental)

-.- Without breakwater (present study)

$\rightarrow$ Breakwater 3

FIGURE 15: RAO curve for a heaving pontoon, with and without breakwater number 3 . 


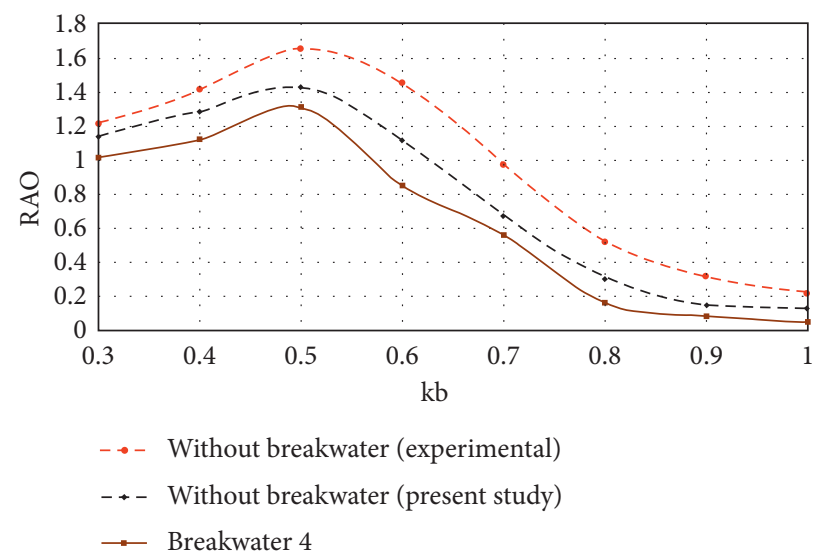

FIGURE 16: RAO curve for a heaving pontoon, with and without breakwater number 4 .

\section{Conclusions}

A 2D numerical model is presented for assessing the performance and efficiency of a submerged trapezoidal breakwater in the vicinity of a floating pontoon in view of incoming waves simulation. To validate the numerical model, two separate test cases are studied. First, the accuracy of the proposed model in simulating the regular waves passing over a submerged breakwater is investigated. As a result, the profiles of the considered wave at four different sections are plotted. It is shown that the accuracy of the model is appropriate for the simulation of the waves before and after the breakwater. Subsequently, a heaving pontoon motion is simulated facing two specified incident waves. The response amplitude operator (RAO) is plotted and compared against experimental data, demonstrating that the exciting frequency of the heaving pontoon motion is fairly close to the incident wave frequency.

Ultimately, a combination model of the two previous test cases is simulated to investigate the efficiency of a submerged trapezoidal breakwater in reducing the response amplitude operator of the heaving pontoon facing regular waves. This is the main novelty of the present which studies the effect of the breakwater in a new form of response amplitude operator (RAO) of a floating structure. Four breakwaters with different dimensions are studied encountering a regular wave. It is demonstrated that the height of a breakwater is much more effective in reducing the wave energy than the length. To be more precise, for a similar breakwater, an increase in the breakwater height would reduce the RAO of the heaving pontoon curve up to $30 \%$ compared to an increase in its length.

\section{Notation}

A: Incident wave amplitude (m)

T: Wave period $(s)$

$k$ : Wavenumber $(\mathrm{rad} / \mathrm{m})$

$\omega$ : Wave angular frequency $(\mathrm{rad} / \mathrm{s})$

$f:$ Wave frequency $(1 / s)$

g: Acceleration due to gravity $\left(9.81 \mathrm{~m} / \mathrm{s}^{2}\right)$

$L:$ Water depth $(\mathrm{m})$ $d$ : Height of pontoon $(\mathrm{m})$

$b$ : Half-breath of pontoon (m).

\section{Data Availability}

Data will be provided upon request to the corresponding author.

\section{Conflicts of Interest}

The authors declare that there are no conflicts of interest.

\section{References}

[1] H. Raman, J. Shankar, and J. Dattatri, "Submerged breakwaters," Central Board of Irrigation and Power Journal, vol. 34, pp. 205-212, 1977.

[2] W. N. Seelig, "Two-dimensional tests of wave transmission and reflection characteristics of laboratory breakwaters," Tech. Rept. No. 80-1, U.S. Army Engineer Research and Development Center, Fort Belvoir, VA, USA, 1980.

[3] D. S. Jeng, C. Schacht, and C. Lemckert, "Experimental study on ocean waves propagating over a submerged breakwater in front of a vertical seawall," Ocean Engineering, vol. 32, no. 1718, pp. 2231-2240, 2005.

[4] D. S. Jeng, Wave-induced seabed response in front of a breakwater, PhD Thesis, The University of Western Australia, Perth, Australia, 1997.

[5] I. E. Alvarez, R. Rubio, and H. Ricalde, "Beach restoration with geotextile tubes as submerged breakwaters in Yucatan, Mexico," Geotextiles and Geomembranes, vol. 25, no. 4-5, pp. 233-241, 2007.

[6] D. Carevic, G. Loncar, and M. Prsic, "Wave parameters after smooth submerged breakwater," Coastal Engineering, vol. 79, pp. 32-41, 2013.

[7] T. M. Dick and A. Brebner, "Solid and permeable submerged breakwaters," in Proceedings of the 11th International Conference on Coastal Engineering, London, UK, September 1968.

[8] N. Kobayashi and A. Wurjanto, "Wave transmission over submerged breakwaters," Journal of Waterway, Port, Coastal, and Ocean Engineering, vol. 115, no. 5, pp. 662-680, 1989.

[9] S. Rojanakamthorn, M. Isobe, and A. Watanabe, "A mathematical model of wave transformation over a submerged breakwater," Coastal Engineering in Japan, vol. 32, no. 2, pp. 209-234, 1989. 
[10] D.-S. Hur and N. Mizutani, "Numerical estimation of the wave forces acting on a three-dimensional body on submerged breakwater," Coastal Engineering, vol. 47, no. 3, pp. 329-345, 2003.

[11] A. C. Rambabu and J. S. Mani, "Numerical prediction of performance of submerged breakwaters," Ocean Engineering, vol. 32, no. 10, pp. 1235-1246, 2004.

[12] H. K. Johnson, T. V. Karambas, I. Avgeris, B. Zanuttigh, D. Gonzalez-Marco, and I. Caceres, "Modelling of waves and currents around submerged breakwaters," Coastal Engineering, vol. 52, no. 10-11, pp. 949-969, 2005.

[13] K. H. Chen and J. T. Chen, "Adaptive dual boundary element method for solving oblique incident wave passing a submerged breakwater," Computer Methods in Applied Mechanics and Engineering, vol. 196, no. 1-3, pp. 551-565, 2006.

[14] M. Christou, C. Swan, and O. T. Gudmestad, "The interaction of surface water waves with submerged breakwaters," Coastal Engineering, vol. 55, no. 12, pp. 945-958, 2008.

[15] H.-K. Chang and J.-C. Liou, "Long wave reflection from submerged trapezoidal breakwaters," Ocean Engineering, vol. 34, no. 1, pp. 185-191, 2007.

[16] Y. Cao, C. Jiang, and Y. Bai, "Numerical study on flow structure near two impermeable trapezoid submerged breakwaters on slop bottoms," Journal of Hydrodynamics, Ser. B, vol. 22, no. 5, pp. 190-196, 2010.

[17] B. Liang, G. Wu, F. Liu, H. Fan, and H. Li, "Numerical study of wave transmission over double submerged breakwaters using non-hydrostatic wave model," Oceanologia, vol. 57, no. 4, pp. 308-317, 2015.

[18] S. Sindhu and K. G. Shirlal, "Prediction of wave transmission characteristics at submerged reef breakwater," Procedia Engineering, vol. 116, pp. 262-268, 2015.

[19] J. Li, Z. Fu, and W. Chen, "Numerical investigation on the obliquely incident water wave passing through the submerged breakwater by singular boundary method," Computers \& Mathematics with Applications, vol. 71, no. 1, pp. 381-390, 2016.

[20] G. Yao, Z. Ma, and B. Ding, "Experimental study on rectangular floating breakwaters," China Ocean Engineering, vol. 7, no. 3, pp. 323-332, 1993.

[21] E. Koutandos, P. Prinos, and X. Gironella, "Floating breakwaters under regular and irregular wave forcing: reflection and transmission characteristics," Journal of Hydraulic Research, vol. 43, no. 2, pp. 174-188, 2005.

[22] D. Sen, "Numerical simulation of motions of two-dimensional floating bodies," Journal of Ship Research, vol. 37, no. 4, pp. 307-330, 1993.

[23] A. N. Williams, H. S. Lee, and Z. Huang, "Floating pontoon breakwaters," Ocean Engineering, vol. 27, no. 3, pp. 221-240, 2000.

[24] R. K. M. Seah and R. W. Yeung, "Sway and roll hydrodynamics of cylindrical sections," International Journal of Offshore and Polar Engineering (ISPOE), vol. 13, no. 4, pp. 241-248, 2003.

[25] E. V. Koutandos, T. V. Karambas, and C. G. Koutitas, "Floating breakwater response to waves action using a boussinesq model coupled with a 2DV elliptic solver," Journal of Waterway, Port, Coastal, and Ocean Engineering, vol. 130, no. 5, pp. 243-255, 2004.

[26] K. A. McTaggart, "Ship capsize risk in a seaway using fitted distributions to roll maxima," Journal of Offshore Mechanics and Arctic Engineering, vol. 122, no. 2, pp. 141-146, 2000.

[27] F. L. Pivert, A. Tizaoui, R. Alexandre, and J.-Y. Billard, "A fully analytical method to assess the risk of capsizing in beam sea,"
Journal of Marine Science and Technology, vol. 22, no. 1, p. 125, 2016.

[28] V. Yakhot and S. A. Orszag, "Renormalization group analysis of turbulence. I. basic theory," Journal of Scientific Computing, vol. 1, no. 1, pp. 3-51, 1986.

[29] V. Yakhot and L. M. Smith, "The renormalization group, the e-expansion and derivation of turbulence models," Journal of Scientific Computing, vol. 7, no. 1, pp. 35-61, 1992.

[30] C. W. Hirt and B. D. Nichols, "Volume of fluid (VOF) method for the dynamics of free boundaries," Journal of Computational Physics, vol. 39, no. 1, pp. 201-225, 1981.

[31] M. Bhinder, M. T. Rahmati, C. G. Mingham, and G. A. Aggidis, "Numerical hydrodynamic modeling of a pitching wave energy converter," European Journal of Computational Mechanics, vol. 24, no. 4, pp. 129-143, 2015.

[32] A. Najafi-Jilani, M. Z. Niri, and N. Naderi, "Simulating three dimensional wave run-up over breakwaters covered by antifer units," International Journal of Naval Architecture and Ocean Engineering, vol. 6, no. 2, pp. 297-306, 2014.

[33] B. Li and C. A. Fleming, "Three-dimensional model of NavierStokes equations for water waves," Journal of Waterway, Port, Coastal, and Ocean Engineering, vol. 1, no. 16, pp. 16-25, 2001.

[34] M. Rodríguez and J. Spinneken, "A laboratory study on the loading and motion of a heaving box," Journal of Fluids and Structures, vol. 64, pp. 107-126, 2016.

[35] WAMIT, WAMIT User Manual:Version 7.0, WAMIT Inc., Chestnut Hill, MA, USA, 2013. 